\title{
Solid Fuel Obtaining by Processing of Coal Enterprises Technogenic Materials
}

\author{
Ushakov Andrey G., Ushakova Elena S., Ushakov Gennady V.
}

\section{Chemical Technology of Solid Fuel of Oil and Gas Technologies Institute, T.F. Gorbachev Kuzbass State Technical University, 650000 Kemerovo, Russia}

\begin{abstract}
The work is devoted to the problem of wastes processing and utilization of coal-mining and coal processing enterprises. It is proposed to use coalwaste in solid composite fuel technologies with the use of innovative binder based on the activated sludge biological treatment facilities. Technological scheme of developed technology is presented.
\end{abstract}

Keywords: coal-mining and coal processing wastes, solid composite fuel, binder.

\section{Introduction}

It is known that the enterprises of the fuel and energy sector, as extractive resources and the receiving of them energy, are the main sources of anthropogenic impact on ecosystems. Intensive development of coal mining and coal processing enterprises have an impact on the lithosphere, causing the increase of volumes of solid carbon-containing wastes with a high percentage of coal sludge materials, screenings and dust. For example, in the mining industry of Russia the total mass of all unprocessed waste reaches 45 billion tons, and the total area occupied for its storage, more than 250 thousand hectares of land ${ }^{[1]}$. It is estimated that the extent of the formation of solid combustible waste in various industries can be from 30 up to $70 \%$ from the basic volume of production.

\section{Characteristic of the work}

Considering the enterprises of a coal mining is possible to allocate the following kinds of waste coal ${ }^{[2,3]}$.
- Coal dust, formed at the enterprises of the coal industry;

- Coal screenings, produced at the enterprises of the fuel and energy sector in the classification of coals and the allocation of factions, suitable for burning in boilers; - Coal sludge - high-ash and micro dispersed particles, which is a waste of technological processes of production of coal. Coal technological wastes are formed in the activities of the coal-mining enterprises - mines, cuts, and also concentrating factories. Sometimes, increasing gross coal production leads to increases loss is more than $50 \%$. The technical condition of many coal preparation plants and their technology are such that the waste coal content of coal reaches 25$26 \%$. One of the negative impacts of coal cuts is air pollution by industrial emissions (from explosions, internal combustion engines and other) and dust particles from the surface of the boards of mines and waste dumps ${ }^{[4,5]}$.

Such amount of waste is an important energy resource that can be the foundation of organization of new kinds of molded fuel production.

But for obtaining high-quality fuel granules with high consumer properties that meet the requirements of durability, abrasion, size, and so on, it is needed for binding substance, which largely depend on the final properties of the product. The choice binder is an important step in determining many of the properties of the received granules. The parameters that define the properties of the binder are the chemical nature, composition, and their physical properties. 
Varieties used binder is quite wide. They can be divided into two broad classes ${ }^{[6,7]}$ : - Organic - concentrates of sulfitno-spirit bards, oil bitumen, pitches and resin oil and coal origin, and so on;

- Inorganic - liquid glass, cement, clay, gypsum binder, bentonite, etc.

Binder requirements to ensure the quality of molding process ${ }^{[8]}$ :

1. High output of fuel (95-98\%) necessary strength to the required standards.

2. Environmental security: the absence of harmful substances in the composition of the binder or the absence of their emission during the subsequent operation of the obtained product.

3. Reliable and stable operation of main and auxiliary equipment for transportation by pipeline raw materials and products, mixing, forming processes.

4. Getting formed fuel that complies with the requirements of the energy companies.

The analysis of binder properties shows that they do not meet all the above requirements.

Thus, there is the problem of search of the optimal binder, which is also easily accessible to the implementation of the molding process and most importantly inexpensive as the economic component in any technology in many respects is crucial.

Products of processing excessive active silt inevitably formed on the stations of biological treatment of industrial and domestic wastewater can use as such substances.

In T.F. Gorbachev Kuzbass State Technical University studies for obtaining solid composite fuel based on waste of the coal enterprises (table 1) and excessive active silt, held microbiological processing (table 2).

Two types of mixtures for the production of fuel granules are reviewed:

1. Coal waste/binder.

2. Coal waste/binder with modifying additives.

To study the influence of the modifying additives on the properties of granules and pelletization progress the mixture was introduced shredded paper weight (table 3).

The basic properties of the received granules are given in table 4 .

The results of laboratory studies are the technological processing scheme of fuel pellets producing (figure).

Table 1. Properties of coal waste

\begin{tabular}{|c|c|c|}
\hline \multicolumn{1}{|c|}{ Parameter } & Coal slurry & Coal screenings \\
\hline Moisture content $\left(\mathrm{W}^{\mathrm{a}}\right), \%$ & 1.6 & 5.3 \\
\hline Ash value $\left(\mathrm{A}^{\mathrm{d}}\right), \%$ & 37.7 & 15.9 \\
\hline Fractional composition, \%: & 11.9 & 73.4 \\
$+1 \mathrm{~mm}$ & 5.8 & 14.4 \\
$1-0,7 \mathrm{~mm}$ & 6.6 & 4.3 \\
$0,7-0,5 \mathrm{~mm}$ & 75.7 & 7.9 \\
$-0,5 \mathrm{~mm}$ & 22.5 & 24.0 \\
\hline The calorific value $\left(\mathrm{Q}_{\mathrm{B}}{ }_{\mathrm{B}}^{\mathrm{d}}\right), \mathrm{MJ} / \mathrm{kg}$ & & \\
\hline
\end{tabular}

Table 2. Characteristics of activated sludge

\begin{tabular}{|c|c|c|c|}
\hline Moisture content $\left(\mathrm{W}^{\mathrm{a}}\right), \%$ & Ash value $\left(\mathrm{A}^{\mathrm{d}}\right), \%$ & Density, кг $/ \mathrm{M}^{3}$ & $\mathrm{~S}$ content, \% \\
\hline $80-90$ & $25-35$ & $1025-1070$ & $0.02-0.05$ \\
\hline
\end{tabular}


Table 3. Formulation of fuel pellets with modifying additives

\begin{tabular}{|l|c|c|}
\hline \multirow{2}{*}{ The components, \% wt. } & \multicolumn{2}{|c|}{ Mixture } \\
\cline { 2 - 3 } & 1 & 2 \\
\hline Coal screenings & 17 & 16 \\
\hline Coal slurry & 44 & 44 \\
\hline Fermented active sludge & 39 & 38 \\
\hline Shredded paper & - & 2 \\
\hline
\end{tabular}

Table 4. Characteristics of fuel granules

\begin{tabular}{|l|c|c|}
\hline \multirow{2}{*}{ Parameter } & \multicolumn{2}{|c|}{ Mixture } \\
\cline { 2 - 3 } & 1 & 2 \\
\hline Ash value $\left(\mathrm{A}^{\mathrm{d}}\right), \%$ & 21 & 26 \\
\hline Resistance to abrasion, \% & 46.3 & 72.2 \\
\hline The calorific value $\left(\mathrm{Q}_{\mathrm{s}}^{\mathrm{d}}\right), \mathrm{MJ} / \mathrm{kg}$ & 21.9 & 22.0 \\
\hline
\end{tabular}

According to the scheme: active sludge treatment plants loaded into the hopper 5, where gyratory pump pumped into the digester 1 , which is subjected to anaerobic digestion with production of biogas. The scheme provides 3 digester, running in parallel. The total period of fermentation is 16 days.

For optimal humidity of the mixture into the digester add water, dosing is carried out automatically (weight batchers). The digestion process is carried out at periodic stirring. The effectiveness of anaerobic digestion is determined by the temperature of fermentation mixture. Optimum temperature of the mixture in the device is $37^{\circ} \mathrm{C}$.

The biogas generated in the process of fermentation, enters the tank 6 , where it is collected and then used for technological needs.

Biogas should be cleaned from acid gases before using. Designed site cleanup (not shown) using ammonia water, in which the acid gases (carbon dioxide, hydrogen sulfide) contact with ammonia - formed ammonium salts, used in various industries. After cleaning, biogas, containing mainly methane (up to 98-99\%), it is proposed to use for space heating and so on, in the home. Consumers of biogas are also being boiler plants, supplying the population with hot water, diesel electrical.

The remaining in the digester at the end of the processing period fermented mass by pump 2 is pumped into the capacity for the preparation of molding mixture, which is served in the granulator 7 .

Received pellets come in a tumble dryer, dried granules sent for packaging and next to the consumer.

\section{Conclusion}

Thus, getting molded fuel based on waste of the coal enterprises using organic binder will solve the problem of waste, and is accompanied by positive economic effect. So for heating the heat carrier up to the same temperature $\left(60^{\circ} \mathrm{C}\right)$, the combustion of various raw materials are spent $2 \mathrm{~kg}$ of firewood, $1.3 \mathrm{~kg}$ of coal and $1.4 \mathrm{~kg}$ developed granules. Designed fuel can be used for heating of private houses and cottages, small and medium-sized boiler-houses.

It is established that the cost of pilot production of 1 ton of fuel pellets on the experimental industrial plant with a capacity of 2500 tons/year of pellets will be 2380 rubles. If scaling up power and industrial plants are conducted, production costs will be reduced by $75 \%$. 







\section{References}

[1] Klimov S.A.,Fraiman G.B., Gruzinov G.P. Complex oil shale using. - Lipeck, 2000. - 179 p.

[2] Shapchenova O.A. The influence of anthropogenic emissions Berezovskaya GRES-1 on biological activity of soils // Environmental Risk: Materials of the 2nd all-Russian conference. - Irkutsk, 2001. p. 182-185.

[3] Volkova A.V. The influence of heatpower engineering on the environment // Modern problems of technical, natural Sciences and Humanities: Materials of the all-Russian conference. P. 1. - Gybkin, 2007. - p. 88-91.

[4] Glazkova A.V., Stroinova V.N. Air pollution from thermal power plants // Problems of geology and exploration of mineral resources: Proceedings of the 3rd academician M.A. Usova International scientific symposium of students, postgraduates and young scientists in the framework of the Russian scientific and social program for youth and schoolchildren Step into the Future - Tomsk, 1999. p. 354-355.

[5] Klika Z., Bartonova L. The effect of different modes of Czech Republic thermal power plants on the behavior of sulfur and minerals coal combustion // Development of Coal Chemistry and Chemistry of Carbon Materials in the XXI Century: Theses of reports of Scientific Council Enlarged sessions, 2003. - M., 2003. - p. 41.

[6] Elishevich A.T. Briquetting of coal with a binder. - M., 1972. $-216 \mathrm{p}$.

[7] Krohin V.N. Briquetting of coal. M.: 1984. -224 p.

[8] Lobuch A.M. Briquetting coke breeze with a binder and coking partially briquetted charge in the manufacture of metallurgical coke: The dissertation for PhD. - Ufa, 2000. - 180 p. 